CLINICAL STUDY

\title{
Relation of plasma homocysteine levels to atherosclerotic vascular disease and inflammation markers in type 2 diabetic patients
}

\author{
Aysen Akalin, Ozkan Alatas ${ }^{1}$ and Omer Colak ${ }^{1}$ \\ Department of Endocrinology, Faculty of Medicine, 26480 Eskisehir Osmangazi University, Eskisehir, Turkey and ${ }^{1}$ Department of Biochemistry, Faculty of \\ Medicine, 26480 Eskisehir Osmangazi University, Eskisehir, Turkey \\ (Correspondence should be addressed to A Akalin; Email: aakalin@superonline.com)
}

\begin{abstract}
Objective: Both hyperhomocysteinemia and increased inflammatory activity are shown to be associated with atherosclerosis. The relation of inflammatory activity to homocysteine (Hcy) levels is not well established. In the present study, we aimed to evaluate the relation of plasma Hcy levels to atherosclerotic vascular disease and inflammatory activity in type 2 diabetic patients.

Design and methods: In total 90 type 2 diabetic patients were included in the study. Of these patients, 41 had established atherosclerotic vascular disease and 49 had no evidence of atherosclerotic vascular disease. Hcy levels and markers of inflammation, namely C-reactive protein, fibrinogen, erythrocyte sedimentation rate, interleukin-6, and tumor necrosis factor $\alpha(\mathrm{TNF} \alpha)$, were measured. Glucose regulation, C-peptide, lipid parameters, and renal functions were also studied.

Results: Both Hcy levels and inflammation markers were all significantly elevated in patients with atherosclerotic vascular disease when compared with patients without vascular disease. Reduced renal functions were responsible for the majority of Hcy elevation in patients with vascular disease. Also, renal functions were significantly associated with both Hcy levels and inflammatory markers. There was no correlation between Hcy levels and inflammation markers except for TNF $\alpha$.

Conclusions: Inflammatory activity and Hcy levels are increased in type 2 diabetic patients with atherosclerotic vascular disease. Impairment of renal functions is the key factor that affects both Hcy levels and inflammation markers. Inflammation is not involved in the process by which Hcy leads atherosclerosis in type 2 diabetes.
\end{abstract}

European Journal of Endocrinology 158 47-52

\section{Introduction}

Diabetes is an important risk factor for atherosclerosis, and atherosclerotic vascular disease is a major cause of morbidity and mortality among patients with diabetes mellitus. Numerous factors including hyperglycemia, hyperlipidemia, hypertension, smoking, endothelial dysfunction, and platelet and coagulation abnormalities contribute to the process of accelerated atherosclerosis in diabetes $(1-3)$.

Atherosclerosis is considered to be an inflammatory process triggered by response to injury. The increase in the plasma inflammation markers were shown to be related with the risk of vascular disease in non-diabetic individuals (4-13). There is evidence suggesting increased inflammatory activity in type 2 diabetic patients (14-16). But the factors that promote this inflammatory process are not apparently clear. C-reactive protein (CRP), fibrinogen, and erythrocyte sedimentation rate (ESR) are well known to be increased in inflammatory conditions $(6-8,11)$. Additionally, interleukin-6 (IL-6) and tumor necrosis factor $\alpha(\mathrm{TNF} \alpha)$ are the main cytokines reflecting the existence of an ongoing inflammation $(13,17)$.

Homocysteine (Hcy) is known to take part in the development of atherosclerosis and vascular injury and it has been suggested to contribute to the atherosclerotic process of diabetes mellitus. Several studies have demonstrated that plasma Hcy levels are elevated in diabetic patients (18-24). But the relation of inflammatory activity to Hcy levels is not well established. The present study was undertaken to compare plasma inflammation markers and Hcy levels in type 2 diabetic patients with and without atherosclerotic vascular disease and to investigate the possible relationship between inflammatory activity and Hcy levels in these patients.

\section{Subjects and methods}

Totally, 90 type 2 diabetic patients were included in the study. Of these patients, 41 had established atherosclerotic vascular disease and 49 had no evidence of 
atherosclerotic vascular disease. Past history of myocardial infarction, coronary artery by-pass surgery, peripheral arterial disease, stroke or angiographically proven coronary artery disease in a patient with electrocardiography (ECG) findings or angina pectoris were considered to be evidence for atherosclerotic vascular disease. Diagnosis of myocardial infarction, peripheral arterial disease, angina pectoris, and stroke were confirmed with appropriate tests by the related sections and were registered in their patient files. The cause of the vascular disease was myocardial infarction or by-pass surgery in 14 patients, stroke in 9 patients, peripheral arterial disease in 7 patients, and in 11 of the patients coronary artery disease was established by angiography. The group without vascular disease was selected from diabetics that have no history of vascular disease, normal ECG on exercise test, and normal peripheral artery Doppler ultrasound. Patients who have experienced myocardial infarction, stroke, diabetic foot infection, and diabetic ketoacidosis in the past 3 months or patients who have infectious diseases were excluded for those conditions could affect inflammatory markers. Age, diabetes duration, and treatment types of the patients were recorded and body mass indices (BMI) were calculated. Only the patients treated with insulin or sulfonylureas were included in the study. None of the patients were taking glitazones, metformin, or insulin plus sulfonylureas. As an index of glomerular filtration rate (GFR), creatinine clearance $(\mathrm{Ccr})$ was calculated using body surface area adjusted Cockroft-Gault formula. In order to exclude possible confounding effects of uremia, patients with creatinine levels above $1.6 \mathrm{mg} / \mathrm{dl}$ were not included in the study. Urinary albumin excretion rates (AER) were measured from 24-h urine collections with an immunoturbidometric assay. Vitamin $\mathrm{B}_{12}$ and folate levels were studied and patients having $\mathrm{B}_{12}$ or folate deficiencies were excluded. Also, thyroid functions were checked and hypo- or hyperthyroid patients were not included in the study. Fasting morning serum and plasma samples were obtained from each patient and hemoglobin A1c (A1c), C-peptide, total cholesterol, triglyceride, high density lipoprotein cholesterol (HDL-C), apolipoprotein A (ApoA), ApoB, lipoprotein a (Lp(a)), CRP, fibrinogen, ESRs were studied. CRP levels were measured nephelometrically (Beckman Image, Beckman Coulter, Fullerton, CA, USA). Fibrinogen levels were measured coagulometrically with Stago Compact analyzer. A1c, HDL-C, triglyceride, total cholesterol, ApoA, ApoB, and Lp(a) levels were studied with RD-Hitachi automatic analyzer using Roche Diagnostic tool kits. Low density lipoprotein cholesterol (LDL-C) was calculated using the Friedwald formula. C-peptide levels were measured by chemiluminescence immunoassay using DPC Immulite autoanalyzer (Diagnostic Products Corporation, Los Angeles, CA, USA). Fasting serum samples were frozen at $-70{ }^{\circ} \mathrm{C}$ without delay and serum IL-6 and $\mathrm{TNF} \alpha$ levels were measured by use of commercially available ELISA kits (Bender Systems, Vienna, Austria). Plasma Hcy levels were measured using ELISA kits (Diazyme, San Diego, CA, USA).

This study was approved by the Ethical Committee of Eskisehir Osmangazi University Medical Faculty.

Student's t-test and Pearson's correlation analysis were performed in statistical evaluation. Multiple regression analysis was used for multivariate analysis. A $P$ value $<0.05$ was accepted as indicating statistical significance. All statistical analyses were performed using SPSS version 10. Results are represented as mean \pm s.D.

\section{Results}

Basic characteristics and clinical variables of the study population are given in Table 1. CRP, ESR, fibrinogen, IL-6, and TNF $\alpha$ levels were significantly higher in patients with atherosclerotic vascular disease than in those without vascular disease. Plasma Hcy levels were also significantly elevated in diabetic patients with atherosclerotic vascular disease. After adjustment for age, diabetes duration, Ccr, AER, and folate levels, Hcy levels persisted to be significantly different between groups except for Ccr and folate.

Parameters found to be significantly correlated with Hcy and inflammation markers are shown in Table 2. The correlation coefficients between the variables were not significantly different among patients with vascular disease and in those without vascular disease when analyzed separately. CRP levels were in negative correlation with $\operatorname{Ccr}(r=-0.263, P=0.012)$ and in positive correlation with AER $(r=0.212, P<0.001)$. We found a significant positive correlation between CRP and triglyceride levels $(r=0.282, P=0.007)$ and a negative correlation with HDL-C levels $(r=-0.400, P<0.001)$.

Fibrinogen levels also correlated negatively with $\mathrm{Ccr}$ $(r=-0.273, P=0.009)$ and positively with AER $(r=0.317, P=0.002)$. ESR levels also correlated negatively with $\operatorname{Ccr}(r=-0.286, P=0.006)$ and positively with AER $(r=0.292, P=0.005)$. We found a negative correlation between ESR levels and HDL-C levels $(r=-0.262, P=0.013)$. Both TNF $\alpha$ and IL-6 levels correlated negatively with HDL-C $(r=-0.295$, $P=0.005 ; r=-0.215, P=0.044)$ and ApoA levels $(r=-0.288, P=0.007 ; r=-0.265, P=0.013$ respectively).There was a significant negative correlation between plasma Hcy levels and Ccr and ApoA levels ( $r=-0.489, P<0.001 ; r=-0.260 P=0.014)$.

It was found by univariate analysis that, among inflammation parameters, there was no correlation between inflammation markers and Hcy levels. Plasma Hcy levels correlated only with TNF $\alpha$ levels significantly ( $r=0.302, P=0.004$; Table 3). However, by multiple regression analysis with Hcy as the dependent variable, the strongest predictors of Hcy were Ccr (negative) and TNF $\alpha$ independent of age, sex, BMI, IL-6, ESR, CRP, fibrinogen, Lp(a), LDL-C, AER, ApoA, hypertension, folate, and $\mathrm{B}_{12}$ (Table 4). 
Table 1 Clinical characteristics and laboratory data of the patients with and without atherosclerotic vascular disease.

\begin{tabular}{|c|c|c|c|}
\hline & $\begin{array}{l}\text { Patients without vascular disease } \\
n=49\end{array}$ & $\begin{array}{l}\text { Patients with vascular disease } \\
n=41\end{array}$ & $\begin{array}{l}\text { Statistical } \\
\text { significance }\end{array}$ \\
\hline Age (years) & $56.24 \pm 1.49$ & $63.75 \pm 1.26$ & $P<0.001^{\ddagger}$ \\
\hline Diabetes duration (years) & $11.00 \pm 0.98$ & $16.87 \pm 1.12$ & $P<0.001^{\ddagger}$ \\
\hline $\mathrm{A} 1_{\mathrm{c}}(\%)$ & $9.80 \pm 0.47$ & $9.55 \pm 0.34$ & \\
\hline $\operatorname{Ccr}\left(\mathrm{ml} / \mathrm{min} \times 1.73 \mathrm{~m}^{2}\right)$ & $79.37 \pm 3.13$ & $62.74 \pm 3.3 .1$ & $P<0.001^{\ddagger}$ \\
\hline $\operatorname{AER}$ (mg/day) & $53.91 \pm 25.11$ & $533 \pm 224.77$ & $P=0.04^{*}$ \\
\hline Cholesterol (mg/dl) & $205.42+7.03$ & $205.97+6.97$ & \\
\hline Triglyceride (mg/dl) & $172.26 \pm 14.36$ & $178.24 \pm 14.67$ & \\
\hline $\mathrm{HDL}-\mathrm{C}(\mathrm{mg} / \mathrm{dl})$ & $46.67 \pm 1.69$ & $42.63 \pm 2.48$ & \\
\hline LDL-C (mg/dl) & $127.24 \pm 6.24$ & $127.97 \pm 6.14$ & \\
\hline ApoA (mg/dl) & $132.36 \pm 3.86$ & $119.48 \pm 4.19$ & $P=0.027^{*}$ \\
\hline ApoB (mg/dl) & $92.31 \pm 3.73$ & $100.12 \pm 4.30$ & \\
\hline $\mathrm{Lp}(\mathrm{a})(\mathrm{mg} / \mathrm{dl})$ & $32.44 \pm 4.04$ & $44.93 \pm 6.52$ & \\
\hline C-peptide $(\mathrm{ng} / \mathrm{ml})$ & $2.96+0.24$ & $2.76+0.27$ & \\
\hline BMI $\left(\mathrm{kg} / \mathrm{m}^{2}\right)$ & $29.49 \pm 0.69$ & $28.98 \pm 0.84$ & \\
\hline CRP (mg/dl) & $0.513 \pm 0.11$ & $1.310 \pm 0.36$ & $P=0.04^{*}$ \\
\hline Fibrinogen (mg/dl) & $386.122 \pm 12.06$ & $457.585 \pm 18.27$ & $P=0.002^{\dagger}$ \\
\hline $\operatorname{ESR}(\mathrm{ml} / \mathrm{h})$ & $17.755 \pm 1.88$ & $32.02 \pm 3.86$ & $P=0.002^{\dagger}$ \\
\hline $\mathrm{TNF} \alpha(\mathrm{pg} / \mathrm{ml})$ & $9.992+1.08$ & $18.419+2.02$ & $P=0.001^{\dagger}$ \\
\hline IL-6 (pg/ml) & $1.428 \pm 0.12$ & $6.117 \pm 1.58$ & $P=0.005^{\dagger}$ \\
\hline $\mathrm{B}_{12}(\mathrm{pg} / \mathrm{ml})$ & $345.25 \pm 132.6$ & $478.42 \pm 535.52$ & $P=0.142$ \\
\hline Folate $(\mathrm{ng} / \mathrm{ml})$ & $12.33 \pm 5.23$ & $10.02 \pm 4.66$ & $P=0.035^{\star}$ \\
\hline Homocysteine ( $\mu \mathrm{mol} / \mathrm{l})$ & $10.725+0.59$ & $13.840+0.95$ & $P=0.005^{\text {a† }}$ \\
\hline Patients with hypertension & $18 / 49$ & $26 / 41$ & $P=0.021^{\star}$ \\
\hline Microalbuminuria & $6 / 49$ & $1 / 41$ & \\
\hline Macroalbuminuria & $14 / 41$ & $8 / 41$ & \\
\hline \multicolumn{4}{|l|}{ Treatment } \\
\hline Sulfonylurea & $43 / 49$ & $22 / 41$ & \\
\hline Insulin & $6 / 49$ & $19 / 41$ & $P=0.001^{\dagger}$ \\
\hline ACEI & $7 / 49$ & $9 / 41$ & \\
\hline Statin & $8 / 49$ & $4 / 41$ & \\
\hline ASA & $19 / 49$ & $15 / 41$ & \\
\hline
\end{tabular}

Data are means \pm S.D. Microalbuminuria: $30 \leq A E R<300 \mathrm{mg} /$ day, Macroalbuminuria: $A E R \geq 300 \mathrm{mg} / \mathrm{day}$

ACEI, angiotensin-converting enzyme inhibitor; statin, HMGCo reductase inhibitor; ASA, acetyl salicylic acid; HDL-C, high density lipoprotein cholesterol; LDL-C, low density lipoprotein cholesterol; Ccr, Creatinine clearance; AER, Albumin excretion rates; ApoA, Apolipoprotein; Lp(a), Lipoprotein a; BMI, Body mass indices; CRP, C-reactive protein; ESR, Erythrocyte sedimentation rate; TNF $\alpha$, Tumor necrosis factor $\alpha$; IL-6, Interleukin-6(IL-6).

${ }^{\text {a } M o d e l ~ 1, ~ a d j u s t e d ~ f o r ~ a g e ; ~} P=0.091$, model 2 , adjusted for diabetes duration; $P=0.012$, model 3 , adjusted for Ccr; $P=0.240$, model 4 , adjusted for AER; $P=0.009$, model 5 , adjusted for folate; $P=0.108$. ${ }^{\star} p<0.05,{ }^{\dagger} p<0.01,{ }^{\ddagger} p<0.001$.

\section{Discussion}

Atherosclerosis is substantially more prevalent, appears earlier, and progresses more rapidly in diabetics when compared with normal population. Even if some of the established cardiovascular risk factors exist more frequently in diabetics, they cannot completely explain this increase in the macrovascular disease (1-3).

Recent investigations have suggested that atherosclerosis is an inflammatory process that is initiated as a response to injury and there is growing evidence on its relationship to inflammation parameters. The association of inflammation with vascular disease is clearly established in non-diabetic individuals $(17,25)$.

There is evidence suggesting increased inflammatory activity in both type 1 and type 2 diabetic patients. Although the precise reason of the increased inflammatory activity is not known, factors such as hyperglycemia, obesity, and hyperinsulinemia are all proposed to affect the inflammatory activity $(11,26)$. There are also reports that connect inflammatory activity to microalbuminuria (27).
In our study, markers of inflammation were all found to be significantly elevated in type 2 diabetic patients with atherosclerotic vascular disease when compared with patients without vascular disease. This finding suggests that inflammatory activity is increased in type 2 diabetics with atherosclerotic vascular disease.

Hcy is also suggested to be a causative factor for atherosclerosis. Hcy levels were found to be elevated in patients with vascular disease and were proposed to contribute to atherosclerosis in patients with coronary artery disease, stroke, and peripheral vascular disease $(1,19,20,22,24,28)$. Hcy-induced vascular pathologies include fragmentation of the internal elastic lamina, disruption of elastic fibers, smooth muscle hyperplasia, and arterial and venous thrombosis (28). It is clear that hyperhomocysteinemia can promote atherosclerosis, but the underlying pathophysiological mechanisms are not well understood. Endothelial cell injury, endothelial dysfunction, increased smooth muscle cell growth, increased platelet adhesiveness, enhanced LDL oxidation and deposition in the arterial wall, and direct activation of the coagulation cascade 
Table 2 Correlation coefficients found to be significant by univariate analysis between inflammatory markers, homocysteine (Hcy) levels, and other cardiovascular risk factors.

\begin{tabular}{|c|c|c|c|c|c|}
\hline & $\begin{array}{l}\text { Ccr } \\
\left(\mathrm{ml} / \mathrm{m} \times 1.73 / \mathrm{m}^{2}\right)\end{array}$ & $\begin{array}{l}\text { AER } \\
\text { (mg/day) }\end{array}$ & $\begin{array}{l}\text { Triglyceride } \\
\text { (mg/dl) }\end{array}$ & $\begin{array}{l}\text { HDL-C } \\
(\mathrm{mg} / \mathrm{dl})\end{array}$ & $\begin{array}{l}\text { ApoA } \\
(\mathrm{mg} / \mathrm{dl})\end{array}$ \\
\hline CRP (mg/dl) & $\begin{array}{l}r=-0.263 \\
P=0.012\end{array}$ & $\begin{array}{l}r=0.212 \\
P=0.045\end{array}$ & $\begin{array}{l}r=0.282 \\
P=0.007\end{array}$ & $\begin{array}{l}r=-0.4 \\
P<0.001\end{array}$ & \\
\hline Fibrinogen (mg/dl) & $\begin{array}{l}r=-0.273 \\
P=0.009\end{array}$ & $\begin{array}{l}r=0.313 \\
P=0.002\end{array}$ & & & \\
\hline $\mathrm{ESR}(\mathrm{mm} / \mathrm{h})$ & $\begin{array}{l}r=-0.28 \\
P=0.006\end{array}$ & $\begin{array}{l}r=0.292 \\
P=0.005\end{array}$ & & $\begin{array}{l}r=-0.262 \\
P=0.013\end{array}$ & \\
\hline IL-6 (pg/ml) & & & & $\begin{array}{l}r=-0.215 \\
P=0.044\end{array}$ & $\begin{array}{l}r=-0.265 \\
P=0.013\end{array}$ \\
\hline $\mathrm{TNF} \alpha(\mathrm{pg} / \mathrm{ml})$ & & & & $\begin{array}{l}r=-0.295 \\
P=0.005\end{array}$ & $\begin{array}{l}r=-0.288 \\
P=0.007\end{array}$ \\
\hline Hcy $(\mu \mathrm{mol} / \mathrm{l})$ & $\begin{array}{l}r=-0.489 \\
P<0.001\end{array}$ & & & & $\begin{array}{l}r=-0.260 \\
P=0.014\end{array}$ \\
\hline
\end{tabular}

HDL-C, high density lipoprotein cholesterol; Ccr, Creatinine clearance; AER, Albumin excretion rates; ApoA, Apolipoprotein; CRP, C-reactive protein; ESR, Erythrocyte sedimentation rate; TNF $\alpha$, Tumor necrosis factor $\alpha$; IL-6, Interleukin-6(IL-6); HCY, Homocysteine.

may all contribute to this process $(1,18,28)$. Several studies have demonstrated that Hcy levels are increased in diabetes. Elevated Hcy levels were shown to be a stronger risk factor in diabetics than in non-diabetic patients $(1,19,20,21,24,29,30)$.

Plasma Hcy levels were also found to be significantly elevated in our type 2 diabetic patients with atherosclerotic vascular disease when compared with patients without vascular disease. However, after correction for variables, it is found that reduced renal functions and low folate levels were responsible for the majority of elevation of Hcy levels. Folate levels were lower in patients with vascular disease though in the normal range. It seems that plasma folate levels are important in the development of vascular disease in diabetics. Since folate levels are essential for the metabolism of Hcy, low folate levels may contribute to vascular disease either by elevating Hcy levels or through other mechanisms. The reason why folate levels were lower in patients with vascular disease is not certain, but supplementation with this nutrient may be beneficial in reducing the risk.

Inflammation markers were shown to be closely related with microalbuminuria and with renal functions that are indicators of renal endothelial injury. However, it is not clear whether inflammation is the cause of the nephropathy or inflammatory activity is elevated in response to nephropathy.

Like CRP and ESR, IL- 6 and TNF $\alpha$ levels were also in a significant negative correlation with HDL-C levels, and in addition they correlated negatively with ApoA levels. It is possible that these cytokines may impair the production or accelerate the catabolism of these lipoproteins that are protective against the atherosclerotic process. Increased inflammatory activity may play a mediator role in the unfavorable serum lipid changes seen in type 2 diabetes.

Plasma Hcy levels are also affected directly by the renal functions and are increased substantially with the decrease in Ccr values. The presence of nephropathy causes elevated plasma Hcy concentrations because of reduced clearance of Hcy $(1,19,21,29)$. Patients with significantly elevated creatinine levels were not included in our study. However, even among diabetic patients with relatively good renal functions, Hcy levels were significantly associated with renal functions.

In literature, both inflammation markers and $\mathrm{Hcy}$ levels were investigated in diabetic patients but there is not much data studying their relationship with each other. In our study, no significant relationship could be found between inflammatory parameters and plasma Hcy levels other than TNF $\alpha$. But it was obvious that both inflammation and Hcy were highly related with renal functions. However, TNF $\alpha$ levels showed a close relationship with Hcy levels. In a study, urinary and interstitial TNF $\alpha$ concentrations were shown to be elevated in diabetic rats before the commencement of microalbuminuria (31). This finding suggests that TNF $\alpha$ may have a role in the complex pathogenesis of diabetic nephropathy. Because the other inflammation markers are not related

Table 3 Pearson correlation coefficients between plasma homocysteine levels and inflammation markers.

\begin{tabular}{|c|c|c|c|c|c|}
\hline & CRP (mg/dl) & Fibrinogen (mg/dl) & $\operatorname{ESR}(\mathrm{mm} / \mathrm{h})$ & IL-6 (pg/ml) & $\operatorname{TNF} \alpha(p g / m l)$ \\
\hline Hcy $(\mu \mathrm{mol} / \mathrm{l})$ & $\begin{array}{l}r=0.146 \\
P=0.175\end{array}$ & $\begin{array}{l}r=0.127 \\
P=0.239\end{array}$ & $\begin{array}{l}r=0.160 \\
P=0.136\end{array}$ & $\begin{array}{l}r=0.053 \\
P=0.623\end{array}$ & $\begin{array}{l}r=0.302 \\
P=0.004\end{array}$ \\
\hline Statistical significance & NS & NS & NS & NS & * 0.00 \\
\hline
\end{tabular}

CRP, C-reactive protein; ESR, Erythrocyte sedimentation rate; TNF $\alpha$, Tumor necrosis factor $\alpha$; IL-6, Interleukin-6(IL-6); HCY, Homocysteine. ${ }^{*} p<0.05$. 
Table 4 Main determinants of homocysteine (Hcy) levels based on multiple regression analysis with Hcy as the dependent variable (model $r^{2}=0.336$; included variables: age, sex, body mass index, C-reactive protein, erythrocyte sedimentation rate, fibrinogen, $L D L$ C, lipoprotein a, apolipoprotein A, tumor necrosis factor $\alpha$ (TNF $\alpha$ ), interleukin-6, creatinine clearance (Ccr), albumin excretion rates, hypertension, folate, $\mathrm{B}_{12}$ ).

\begin{tabular}{lrr}
\hline Independent predictors & $\boldsymbol{\beta}$ & \multicolumn{1}{c}{$p$} \\
\hline $\mathrm{TNF} \alpha$ & 0.296 & 0.003 \\
$\mathrm{Ccr}$ & -0.471 & $<0.001$ \\
\hline
\end{tabular}

with Hcy in our study, the relation of TNF $\alpha$ with Hcy levels seems to be through another factor related with atherosclerosis.

Since we did not study the levels of insulin resistance in our subjects, we could not exclude entirely that the association found between Hcy and TNF $\alpha$ might be due to insulin resistance. However, we could not show any relationship between these parameters and C-peptide levels and BMI of the patients that are indirect measures reflecting insulin resistance. Alternatively, insulin resistance may activate a common mechanism elevating both Hcy and TNF $\alpha$ levels. However, our findings are not sufficient to explain the exact nature of the association between these two variables.

In the study conducted by Aso Y and colleagues, inflammation markers IL-6, hsCRP, and fibrinogen levels were found to be significantly correlated with Hcy levels in patients with diabetic nephropathy. However, when they reevaluated the findings after adjustment for Ccr, none of the inflammation markers except IL-6 (IL-6 correlated with Hcy; $P=0.05$ ) remained to be significantly correlated with Hcy. Also, an association of plasma Hcy with IL-6 and C-peptide levels was shown in another study in type 2 diabetic patients, and insulin resistance was thought to be the common mechanism leading both Hcy and IL-6 elevations (32).

There are also studies investigating the relation of Hcy levels to inflammation in patients with coronary artery disease, in elderly patients, etc. with some inconsistent results suggesting a causal relationship between them $(33,34)$. But in all these studies, they did not take into account the GFRs of the patients. Moreover, lowering of Hcy levels by means of folic acid, pyridoxine, or cyanocobalamin did not influence the inflammatory responses $(34,35)$. In a study conducted in patients with chronic kidney disease starting dialysis therapy, markers of inflammation were found to be negatively correlated with Hcy levels (36).

Also, Hcy was not found to be associated with lowgrade inflammation in a population with and without type 2 diabetes (37). Likewise, in another study, both Hcy and inflammation markers were found to be elevated in chronic renal failure patients. But, while there was no association between Hcy levels and oxidative stress, hemostatic activation and endothelial dysfunction, these parameters were closely associated with inflammation parameters. These findings suggest that inflammation is not involved in the process by which Hcy leads atherosclerosis (38).

In type 2 diabetic patients, inflammatory activity can be a significant indicator of vascular disease and endothelial damage. Although Hcy elevation is also a correlate of atherosclerotic vascular disease, the connection of atherosclerosis to Hcy is not through inflammation. Impairment of renal functions is the key factor that affects both inflammation and Hcy levels. Hcy may lead to atherosclerosis by operating through alternative mechanisms other than inflammation.

\section{References}

1 Audelin MC \& Genest J, Jr. Homocysteine and cardiovascular disease in diabetes mellitus. Atherosclerosis 2001159 497-511.

2 Grundy SM, Benjamin IJ, Burke GL, Chait A, Eckel RH, Howard BV, Mitch W, Smith SC, Jr \& Sowers JR. Diabetes and cardiovascular disease: a statement for healthcare professionals from the American Heart Association. Circulation 1999100 1134-1146.

3 Najemnik C, Sinzinger H \& Kritz H. Endothelial dysfunction, atherosclerosis and diabetes. Acta Medica Austriaca 199926 148-153.

4 Blake GJ \& Ridker PM. Novel clinical markers of vascular wall inflammation. Circulation Research 200189 763-771.

5 Farmer JA \& Torre-Amione G. Atherosclerosis and inflammation. Current Atherosclerosis Reports 20024 92-98.

6 Eriksen G, Liestol K, Bjornholt JV, Stormorken H, Thaulow E \& Eriksen J. Eritrocyte sedimentation rate: a possible marker of atherosclerosis and a strong predictor of coronary heart disease mortality. European Heart Journal 200021 1614-1620.

7 Folsom AR, Pankow JS, Russell PT, Arnett DK, Peacock JM, Hong Y, Djousse L, Eckfeldt JH \& Investigators of the NHLBI Family Heart Study. Association of C-reactive protein with markers of prevalent atherosclerotic disease. American Journal of Cardiology 200188 112-117.

8 Weintraub WS \& Harrison DG. C-reactive protein, inflammation and atherosclerosis: do we really understand it yet? European Heart Journal 200021 958-960.

9 Colhoun HM, Rubens MB, Schalkwijk C \& Stehouwer CDA. C-reactive protein in type 1 diabetes and its relationship to coronary artery calcification. Diabetes Care 200225 1813-1817.

10 Haidari M, Javadi E, Sadeghi B, Hajilooi M \& Ghanbili J. Evaluation of C-reactive protein, a risk factor for stable coronary artery disease. Clinical Biochemistry 200133 309-315.

11 Klein RI, Hunter S, Jenkins AJ, Zheng D, Semler AJ, Clore J, Garvey WT \& The DCCT/EDIC Study Group. Fibrinogen is a marker for nephropathy and peripheral vascular disease in type 1 diabetes. Diabetes Care 200326 1439-1448.

12 Pepys MB \& Hirschfield GM. C-reactive protein and atherotrombosis. Italian Heart Journal 20012 196-199.

13 Elkind MS, Cheng J, Boden-Albala B, Rundek T, Thomas J, Chen H, Rabbani LE \& Sacco RL. Tumor necrosis factor receptor levels are associated with carotid atherosclerosis. Stroke 200233 31-38.

14 Jager A, Van Hinsberg VW, Kostense PJ, Emeis JJ, Yudkin JS, Nijpels G, Dekker JM, Heine RJ, Bouter LM \& Stehouwer CD. Von Willebrand factor, C-reactive protein, and 5-year mortality in diabetic and nondiabetic subjects: the Hoorn Study. Arteriosclerosis, Thrombosis, and Vascular Biology 199919 3071-3078.

15 Stehouwer CD, Gall MA, Twisk JW, Knudsen E, Emeis JJ \& Parving HH. Increased urinary albumin excretion, endothelial dysfunction and chronic low-grade inflammation in type 2 diabetes:progressive, interrelated, and independently associated with risk of death. Diabetes 200251 1157-1165. 
16 Ceriello A, Taboga C, Giacomello R, Falleti E, DeStasio G, Motz E, Lizzio S, Gonano F \& Bartoli E. Fibrinogen plasma levels as a marker of thrombin activation in diabetes. Diabetes 199443 430-432.

17 Papanicolaou DA, Wilder R, Manolagas SC \& Chrousos GP. The pathophysiologic roles of interleukin-6 in human disease. Annals of Internal Medicine $1998 \mathbf{1 2 8} 127-137$.

18 Fonseca V, Guba SC \& Fink LM. Hyperhomocysteinemia and the endocrine system: implications for atherosclerosis and thrombosis. Endocrine Reviews 199920 738-779.

19 Hofmann MA, Kohl B, Zumbach MS, Borcea V, Bierhaus A, Henkels M, Amiral J, Schmidt AM, Fiehn W, Ziegler R, Wahl P \& Nawroth PP. Hyperhomocysteinemia and endothelial dysfunction in IDDM. Diabetes Care 199821 841-847.

20 Okada E, Oida K, Tada H, Asazuma K, Eguchi K, Tohda G, Kosaka S, Takahashi S \& Miyamori I. Hyperhomocysteinemia is a risk factor for coronary arteriosclerosis in Japanese patients with type 2 diabetes. Diabetes Care 199922 484-490.

21 Buysschaert M, Dramais AS, Wallemacq PE \& Hermans MP. Hyperhomocysteinemia in type 2 diabetes. Diabetes Care 200023 1816-1822.

22 Koning ABL, Werstuck GH, Zhou J \& Austin RC. Hyperhomocysteinemia and its role in the development of atherosclerosis. Clinical Biochemistry 200336 431-441.

23 Knect P, Reunanen A, Alfthan G, Heliovaara M, Rissanen H, Marniemi J \& Aroma A. Hyperhomocysteinemia: a risk factor or a consequence of coronary heart disease? Archives of Internal Medicine 2001161 1589-1594.

24 Abdella NA, Mojiminiyi OA, Akanji AO \& Moussa MA. Associations of plasma homocysteine concentration in subjects with type 2 diabetes mellitus. Acta Diabetologica 200239 183-190.

25 Mendall MA, Patel P, Balam L, Strachan D \& Northfield TC. C reactive protein and its relation to cardiovascular risk factors: a population based cross sectional study. BMJ 1996312 1061-1065.

26 Schram MT, Chaturvedi N, Schalkwijk C, Giorgino F, Ebeling P, Fuller JH, Stehouwer CD \& The Eurodiab Prospective Complications Study Group. Vascular risk factors and markers of endothelial function as determinants of inflammatory markers in type 1 diabetes. Diabetes Care 200326 2165-2173.

27 Festa A, D’Agostino R, Howard G, Jr, Mykkanen L, Tracy RP \& Haffner SM. Inflammation and microalbuminuria in nondiabetic and type 2 diabetic subjects: the Insulin Resistance Atherosclerosis Study. Kidney International 200058 1703-1710.

28 Lentz SR. Mechanisms of homocysteine-induced atherothrombosis. Journal of Thrombosis and Haemostasis 20053 1646-1654.

29 Aso Y, Yoshida N, Okumura K, Wakabayashi S, Matsumoto R, Takebayashi K \& Inukai T. Coagulation and inflammation in overt diabetic nephropathy: association with hyperhomocysteinemia. Clinica Chimica Acta 2004348 139-145.
30 Becker A, Kostense PJ, Bos G, Heine RJ, Dekker JM, Nijpels G, Bouter LM \& Stehouwer CDA. Hyperhomocysteinaemia is associated with coronary events in type 2 diabetes. Journal of Internal Medicine 2003252 293-300.

31 Kalantarinia K, Awad AS \& Siragy HM. Urinary and renal interstitial concentrations of TNF- $\alpha$ increase prior to the rise in albuminuria in diabetic rats. Kidney International 200364 1208-1213.

32 Araki A, Hosoi T, Orimo H \& Ito H. Association of plasma homocysteine with serum interleukin-6 and C-peptide levels in patients with type 2 diabetes. Metabolism: Clinical and Experimental 200554 809-814.

33 Gori AM, Corsi AM, Fedi S, Gazini A, Sofi F, Bartali B, Bandinelli S, Gensini GF, Abbate R \& Ferruci L. A proinflammatory state is associated with hyperhomocysteinemia in the elderly. American Journal of Clinical Nutrition 200582 335-341.

34 Jonasson T, Ohlin AK, Gottsater A, Hultberg B \& Ohlin H. Plasma homocysteine and markers for oxidative stress and inflammation in patients with coronary artery disease - a prospective randomized study of vitamin supplementation. Clinical Chemistry and Laboratory Medicine $2005 \mathbf{4 3} 628-634$.

35 Durga J, van Tits LJ, Schouten EG, Kok FJ \& Verhoef P. Effect of lowering homocysteine levels on inflammatory markers: a randomized controlled trial. Archives of Internal Medicine 2005 165 1388-1394.

36 Suliman ME, Stenvinkel P, Qureshi R, Barany P, Heimburger O, Anderstam B, Alvestrand A \& Lindholm B. Hyperhomocysteinemia in relation to plasma free amino acids, biomarkers of inflammation and mortality in patients with chronic kidney disease starting dialysis therapy. American Journal of Kidney Diseases 20043 455-465.

37 Becker A, van Hinsbergh VWM, Kostense PJ, Jager A, Dekker JM, Nijpels G, Heine RJ, Bouter LM \& Stehouwer CDA. Serum homocysteine is weakly associated with von Willebrand factor and soluble vascular adhesion molecule I, but not with C-reactive protein in type 2 diabetic and non-diabetic subjects - The Hoorn Study. European Journal of Clinical Investigation 200030 763-770.

38 Mezzano D, Pais EO, Aranda E, Panes O, Downey P, Ortiz M, Tagle R, Gonzales F, Quirga T, Caceres MS, Leighton F \& Preira J. Inflammation, not hyperhomocysteinemia, is related to oxidative stres and hemostatic and endothelial dysfunction in uremia. Kidney International $2001601844-1850$.

Received 23 September 2007

Accepted 21 October 2007 